\title{
HutZ is required for biofilm formation and contributes to the pathogenicity of Edwardsiella piscicida
}

\author{
Yan-Jie Shi ${ }^{1,2}$, Qing-Jian Fang ${ }^{2}$, Hui-Qin Huang ${ }^{1,2,4}$, Chun-Guang Gong ${ }^{1 *}$ and Yong-Hua Hu 1,2,3,4* $^{*}$
}

\begin{abstract}
Edwardsiella piscicida is a severe fish pathogen. Haem utilization systems play an important role in bacterial adversity adaptation and pathogenicity. In this study, a speculative haem utilization protein, HutZ $Z_{\mathrm{Ep}}$, was characterized in $E$. piscicida. hut $Z_{E p}$ is encoded with two other genes, hutW and hut $X$, in an operon that is similar to the haem utilization operon hutWXZ identified in $V$. cholerae. However, protein activity analysis showed that HutZ $Z_{E p}$ is probably not related to hemin utilization. To explore the biological role of HutZ $Z_{E p}$ a markerless hut $Z_{E p}$ in-frame mutant strain, $T X 01 \Delta h u t Z$, was constructed. Deletion of hut $Z_{E p}$ did not significantly affect bacterial growth in normal medium, in iron-deficient conditions, or in the presence of haem but significantly retarded bacterial biofilm growth. The expression of known genes related to biofilm growth was not affected by hut $Z_{E p}$ deletion, which indicated that Hut $Z_{\text {Ep }}$ was probably a novel factor promoting biofilm formation in E. piscicida. Compared to the wild-type TX01, TX01 $\triangle$ hutZ exhibited markedly compromised tolerance to acid stress and host serum stress. Pathogenicity analysis showed that inactivation of hut $Z_{E p}$ significantly impaired the ability of E. piscicida to invade and reproduce in host cells and to infect host tissue. In contrast to TX01,TX01 $\triangle$ hutZ was defective in blocking host macrophage activation. The expression of hutZ $Z_{E p}$ was directly regulated by the ferric uptake regulator Fur. This study is the first functional characterization of HutZ in a fish pathogen, and these findings suggested that $\mathrm{HutZ}_{\mathrm{Ep}}$ is essential for E. piscicida biofilm formation and contributes to host infection.
\end{abstract}

\section{Introduction}

Iron is an essential element for bacteria because it is necessary for a wide variety of physiological processes, including electron transfer, enzyme catalysis, energy transduction, and regulation of gene expression [1,2]. Iron also plays a key role in host-pathogen interactions in animals and plants, so iron is necessary for bacterial invasion and successful infection [3, 4]. Although iron is the most abundant metallic element on earth, the majority of iron is sequestered in iron- and haem-containing proteins within the host, so iron deficiency is the most common nutritional stress for bacteria $[5,6]$. Therefore,

\footnotetext{
*Correspondence: Gongcg2005@163.com; huyonghua@itbb.org.cn

1 Ocean College of Hebei Agricultural University, Qinhuangdao 066000,

China

${ }^{2}$ Institute of Tropical Bioscience and Biotechnology, Chinese Academy

of Tropical Agricultural Sciences, Haikou 571101, China

Full list of author information is available at the end of the article
}

bacterial pathogens have developed a variety of strategies that facilitate the uptake and utilization of iron $[1$, 3]. Since the overwhelming majority of iron in the host is present as haem iron [7], haem is a dominant iron source for most pathogenic bacteria [7, 8]. It is not surprising that many bacterial pathogens have evolved elaborate strategies to acquire haem from host sources, which are important for pathogenesis $[7,9]$. One of these strategies is haem uptake systems, and the utilization of haem is a common mechanism employed by pathogens [10].

Haem uptake systems in gram-negative bacteria consist of outer membrane receptors that either directly bind haem and haemoproteins or bind haem-bound secreted haemophores. Haem then transits the periplasm and is brought into the cell via $\mathrm{ABC}$ transporters in the inner membrane [9]. There are several types of mechanisms for haem uptake and utilization in gram-negative bacteria. A universal haem uptake system usually involves 
outer membrane receptors, a TonB-dependent internalization process, a periplasmic binding protein, and an inner membrane-associated $\mathrm{ABC}$ transporter, which has been identified in numerous species, including Escherichia coli, Vibrio cholerae, and Vibrio anguillarum [11]. Another mechanism for haem uptake is mediated by a haem-binding outer membrane lipoprotein, as in Haemophilus influenzae [12]. The opportunistic pathogen Pseudomonas aeruginosa encodes direct haem uptake and haemophore systems at the outer membrane [13], and Neisseria meningitidis uses a unique bipartite receptor for haem acquisition from host haemoproteins [14].

The mechanism of haem transfer from outside the cell to the cytoplasm of bacteria has been extensively studied; however, little is known about the fate of haem after it enters the cytoplasm. A haem utilization operon, hutWXZ, has been identified in $V$. cholerae [15-17]. A similar operon, $h u g W X Z$, was also identified in Plesiomonas shigelloides [18]. hutWXZ and hugWXZ were considered necessary for obtaining iron from haem $[17,18]$. In $E$. coli, a haem utilization gene cluster, chu, was identified that encodes a series of proteins, including ChuS, ChuA, ChuT, ChuW, ChuX, ChuY, and ChuU [19, 20]. ChuW and $\mathrm{ChuX}$ are homologous to HutW and HutX, which constitute the ChuW_HutW and ChuX_HutX superfamilies, respectively. HutW belongs to the S-adenosylmethionine (SAM) radical superfamily and was predicted to serve as an electron carrier for HutZ [17]. ChuW is a radical $S$-adenosylmethionine methyltransferase that catalyses a radical-mediated mechanism facilitating iron liberation and the production of the tetrapyrrole product termed "anaerobilin", which can be used as a substrate by ChuY [21]. HutX is a cytoplasmic haem transport protein for HutZ, and haem is transferred from HutX to HutZ via a specific protein-protein interaction [17]. ChuX binds haem with a stoichiometry of $1: 1$, and ChuX is characterized as a haem-trafficking protein [19]. The third protein of the HutWXZ system in V. cholerae, HutZ, is a cytoplasmic haem-binding protein that has been identified as a haem-degrading enzyme [17]. However, ChuY, the counterpart of HutZ, has relatively low homology with HutZ. ChuY has high structural homology with human biliverdin and flavin reductase. It has been reported that ChuY has flavin mononucleotide (FMN) reductase activity, using $\mathrm{NAD}(\mathrm{P}) \mathrm{H}$ as a cofactor, and shows porphyrin ring binding affinity $[19,20]$. Moreover, ChuY acts as a reductase in haem homeostasis to maintain the virulence potential of E. coli CFT073 [21].

Edwardsiella piscicida (formerly included in the Edwardsiella tarda species) [22, 23], a family member of Enterobacteriaceae, is a serious fish pathogen and has a broad host range that includes many species of economically important fish, such as Japanese eel, flounder, turbot, red sea bream, tilapia, and channel catfish [24]. Recently, an increasing number of studies on E. piscicida have been reported. A large number of virulence factors/systems, such as type III (T3SS) and type VI (T6SS) secretion systems, the LuxS/AI-2 quorum sensing system, molecular chaperons, the RNA-binding protein Hfq, ferric uptake regulator (Fur), and lysozyme inhibitors, are known to be involved in E. piscicida stress resistance, host immune escape, and pathogenicity [25-31]. However, study of haem uptake and utilization by E. piscicida is extremely limited.

There is a speculative haem utilization operon in the $E$. piscicida genome; the first two proteins were annotated as ChuW/HutW and ChuX/HutX, and the third protein was annotated as an epimerase [32]. According to sequence homology comparison and other pathogenic bacterial sequence information, we named the third protein in this speculative haem utilization operon HutZ. In this study, we characterized HutZ in E. piscicida (named Hut $Z_{\mathrm{Ep}}$ ), examined its expression profiles under different conditions, and analysed its role in adversity and infection. Our results provide the first insights into the biological function of E. piscicida HutZ.

\section{Materials and methods}

\section{Bacteria and growth conditions}

Escherichia coli BL21 (DE3) was purchased from TransGen (Beijing, China). E. coli S17-1 $\lambda$ pir was purchased from Biomedal (Sevilla, Spain). E. piscicida TX01 was isolated from diseased fish [33]. Bacteria were cultured in Luria-Bertani broth (LB) at $37{ }^{\circ} \mathrm{C}$ (for E. coli) or $28{ }^{\circ} \mathrm{C}$ (for E. piscicida). Where indicated, chlorampheni$\mathrm{col}$, tetracycline, and polymyxin B were supplemented at concentrations of $30 \mu \mathrm{g} / \mathrm{mL}, 15 \mu \mathrm{g} / \mathrm{mL}$, and $100 \mu \mathrm{g} / \mathrm{mL}$, respectively; $2,2^{\prime}$ dipyridyl $(\mathrm{Dp})$ was supplemented at concentrations of $60 \mu \mathrm{M}, 100 \mu \mathrm{M}$, or $150 \mu \mathrm{M}$; and haem was supplemented at concentrations of $0.5 \mu \mathrm{M}$ or $20 \mu \mathrm{M}$.

\section{Construction of the hut $Z_{E p}$ mutation and its complementation}

The primers used in this study are listed in Table 1. To construct a $h u t Z_{E p}$ knockout strain, TX01 $\Delta h u t Z$, inframe deletion of a $441 \mathrm{bp}$ segment (residues 13 to 453 ) of hut $Z_{E p}$ was performed by overlap extension PCR as follows: the first overlap PCR was performed with the primer pair HutZF1/R1, the second overlap PCR was performed with the primer pair HutZF2/R2, and the fusion PCR was performed with the primer pair HutZF1/R2. The PCR products amplified by the primer pair HutZF1/ $\mathrm{R} 2$ were inserted into the suicide plasmid $\mathrm{pDM} 4$ at the BglII site, resulting in pDMHutZ. S17-1 $\lambda$ pir was transformed with $\mathrm{pDMHutZ}$, and the transformants were conjugated with TX01 as described previously [34]. The 
Table 1 Primers used in this study

\begin{tabular}{ll}
\hline Primer name & Sequence $\left(\mathbf{5}^{\prime} \mathbf{- 3}^{\prime}\right.$ ) \\
\hline HutZKOF1 & GGATCCTTAGCGCTGGTGCACAC (BamHI) \\
HuttZKOR1 & TCCAGCAACCACGGCGTCATGCGCGC \\
HutZKOF2 & CGCCGTGGTTGCTGGATGGCGAAGCC \\
HutZKOR2 & GGATCCCAGCATTTCCGGCGCGGAT (BamHI) \\
HutZF3 & ACACATTGCACTGGTTGA \\
HutZR3 & GTACGCTCTTGCGTCAGT \\
HutZRTF & GCAGAGCAGCGGTATGGACTTT \\
HutZRTR & TTCCATCAGGCGGTACATCCA \\
HutZF5 & GAGCTCATGACGCCGTGGTC (SaCl) \\
HutZR5 & AAGCTTGCGCACGGGGCGCTC (HindIII) \\
HutZF1 & CATATGATGACGCCGTGGATC (Ndel) \\
HutZR1 & CTCGAGGCGCACGGGGCGCTC (Xhol) \\
HutWXF & AGTGGCAATCCTGCGATTT \\
HutWXR & TGTTGATAAGCGTGGTGACA \\
HutXZF & CGTGTGGTTTATCAACCCTG \\
HutXZR & TGGGCGAGATAGTCATGACC \\
HutPF4 & ATTTAAATGCCCGGACAGGCGCTGAT (Swal) \\
HutPR4 & ATTTAAATGGTAACTCTCCGTTAATACCTGA (Swal) \\
FurF1 & GGATCCATGACTGACAACAACACC (BamHI) \\
FurR1 & AAGCTTGGCCTTTTCGTCGTGCA (HindIII) \\
\hline
\end{tabular}

transconjugants were selected on LB agar plates supplemented with $10 \%$ sucrose. One of the colonies that were resistant to sucrose and sensitive to chloramphenicol was analysed by PCR, and the PCR products were subjected to DNA sequencing to confirm in-frame deletion. This strain was named TX01 $h u t Z$. To construct the complementary strain TX01 $h u t Z C, h u t Z_{E p}$ was amplified by PCR with the primers HutZF3/R3, and the following experimental operations were performed, as described previously [34].

\section{Resistance to acidic stress and to non-immune fish serum}

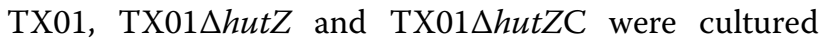
in LB medium to exponential phase. To determine acid tolerance, $\mathrm{LB}$ agar plates with $\mathrm{pH}=7$ or $\mathrm{pH}=5$ were streaked with the three bacteria. The plates were incubated at $28{ }^{\circ} \mathrm{C}$ for $48 \mathrm{~h}$, and bacterial growth was examined. For quantitative analysis, three strains were cultured in LB medium with acid stress conditions for $24 \mathrm{~h}$, and then the populations of cultivated bacteria were counted by dilution plating. The experiment was performed three times.

TX01, TX01 $4 h u t Z$ and TX01 $\Delta h u t Z C$ were cultured in LB medium to exponential phase. Then, the cells were washed with PBS and resuspended in PBS. Approximately $10^{5}$ bacterial cells were mixed with $50 \mu \mathrm{L}$ of fish serum or PBS (control). After incubation with mild agitation at $23{ }^{\circ} \mathrm{C}$ for $60 \mathrm{~min}$, the mixtures were serially diluted and plated in triplicate on LB agar plates. The plates were incubated at $28{ }^{\circ} \mathrm{C}$ for $48 \mathrm{~h}$, and the colonies that appeared on the plates were enumerated. The survival rate was calculated as follows: [(number of serum-treated cells) $/$ (number of control cells) $] \times 100 \%$. The experiment was performed three times.

\section{Biofilm assay and motility assay}

TX01 and TX01 $\Delta$ hutZ were cultured in LB medium to exponential phase and diluted to $10^{6} \mathrm{CFU} / \mathrm{mL}$. The diluted cells were transferred into a 96-well polystyrene plate (Nunc, Denmark) and incubated at $28{ }^{\circ} \mathrm{C}$ for $24 \mathrm{~h}$ without agitation. Then, the wells were washed gently five times with PBS. The attached cells were treated with Bouin fixative for $1 \mathrm{~h}$ and stained with $1 \%$ crystal violet solution for $20 \mathrm{~min}$. After the treatment, unbound dye was removed by rinsing the plate several times with PBS. The plate was air dried. Bound dye was eluted in methanol, and the $A_{570}$ of eluates was measured. The experiment was performed three times.

The observation of biofilms by confocal laser scanning microscopy (CLSM) was performed as described by Chan et al. [35]. Briefly, TX01 and TX01 $\Delta h u t Z$ were grown in LB medium on glass-bottom dishes for $24 \mathrm{~h}$ at $28{ }^{\circ} \mathrm{C}$. The dishes were rinsed to remove non-adherent bacteria and then stained with a LIVE/DEAD BacLight bacterial viability kit L-13152 (Invitrogen-Molecular Probes, Carlsbad, CA, USA) for observation of biofilms. The staining procedure involved incubation for $15 \mathrm{~min}$ at room temperature in the dark. The biofilms were observed using a Leica TCS-SP2-AOBS-UV confocal laser scanning microscope equipped with an argon ion laser. The observation of biofilms was also performed with a stereoscopic fluorescence microscope as described by Hufnagel et al. [36]. Briefly, TX01 and TX01 4 hutZ were grown in $\mathrm{LB}$ medium to an $\mathrm{OD}_{600}$ of 0.6 , washed twice in YESCA broth (10 $\mathrm{g}$ of casamino acids and $1 \mathrm{~g}$ of yeast extract/L) and spotted onto YESCA CR $(50 \mu \mathrm{g} / \mathrm{mL})$ medium for $48 \mathrm{~h}$ at $28^{\circ} \mathrm{C}$. The biofilms were observed by stereoscopic fluorescence microscopy.

To measure motility, TX01 and TX01 $\Delta h u t Z$ were cultured in $\mathrm{LB}$ medium to an $\mathrm{OD}_{600}$ of 1.0 , and $2 \mu \mathrm{L}$ of cell suspensions were spotted onto the centre of fresh swimming plates, which contained LB medium plus $0.3 \%(\mathrm{w} / \mathrm{v})$ agar. The plates were then incubated at $28^{\circ} \mathrm{C}$. After $48 \mathrm{~h}$, the motility of the bacteria was assessed by examining the diameter of the motility halo on the soft agar. The experiment was performed three times.

\section{Invasion of host cell lines}

Examination of interactions between FG cells and $E$. piscicida was performed as described previously [37]. Briefly, FG cells were cultured in 96-well cell culture 
plates to a monolayer and mixed with the strain TX01 or TX01 $\Delta u t Z$ at a multiplicity of infection (MOI) of 10:1. After incubation at $25^{\circ} \mathrm{C}$ for $1 \mathrm{~h}$ and $2 \mathrm{~h}$, the plates were washed three times with PBS. To determine the number of bacterial cells associated with the entire FG cell, the washed FG cells were lysed with $200 \mu \mathrm{L}$ of $1 \%$ (vol/vol) Triton X-100 in PBS, and the number of bacteria was counted by dilution plating. To determine the numbers of bacterial cells that had penetrated into FG cells, the abovementioned washed FG cells were incubated with gentamicin $(100 \mu \mathrm{g} / \mathrm{mL})$ for $2 \mathrm{~h}$ to kill extracellular bacteria. After washing three times with PBS, the cells were incubated for $0 \mathrm{~h}$ to $8 \mathrm{~h}$. FG cells were lysed and plated as described above.

\section{Fish and experimental challenges for bacterial dissemination in vivo}

Clinically healthy Japanese flounder (Paralichthys olivaceus) (average $12.8 \mathrm{~g}$ ) were purchased from a commercial fish farm of Shandong. The fish were maintained at $\sim 22{ }^{\circ} \mathrm{C}$ in aerated seawater and fed daily with commercial dry pellets. Fish were acclimatized in the laboratory for 2 weeks. Before the experiment, fish were randomly sampled and examined for the presence of bacteria in the blood, liver, kidney, and spleen, and no bacteria were detected from the sampled fish, as described previously [38]. For tissue collection, fish were euthanized with an overdose of MS222 (tricaine methanesulfonate) (Sigma, USA). For tissue dissemination analysis, TX01, TX01 $4 h u t Z$, and TX01 $4 h u t Z C$ were cultured in LB medium to an $\mathrm{OD}_{600}$ of 0.6 . The cells were washed with PBS and resuspended in PBS to $10^{6} \mathrm{CFU} / \mathrm{mL}$. Fish were divided randomly into four groups and infected by intraperitoneal injection with $50 \mu \mathrm{L}$ of TX01, TX01 $4 h u t Z$, TX01 $\Delta$ hutZC, or PBS. The kidney and spleen were taken aseptically from the fish at $24 \mathrm{~h}$ and $48 \mathrm{~h}$ post-infection (hpi). Bacterial recovery from the tissues was determined as reported previously [33]. The experiment was performed in triplicate.

\section{Reactive oxygen species (ROS) production}

Flounder head kidney (HK) macrophages were prepared as described previously [39]. ROS production was determined as follows. Flounder HK macrophages in a 96-well microplate $\left(\sim 10^{5}\right.$ cells/well $)$ were incubated with TX01, TX01 $h u t Z$, and TX01 4 hutZC $\left(10^{6} \mathrm{CFU} /\right.$ well) for $2 \mathrm{~h}$. The plate was washed with PBS three times. One hundred microliters of $1 \mathrm{mg} / \mathrm{mL}$ nitroblue tetrazolium (Sangon, Shanghai, China) in L-15 was added to the cells. After incubation at $25{ }^{\circ} \mathrm{C}$ for $2 \mathrm{~h}$, the reaction was stopped by adding $100 \%$ methanol. The plate was washed with $70 \%$ methanol, and reduced formazan was solubilized in $100 \mu \mathrm{L}$ of $2 \mathrm{M} \mathrm{KOH}$ and $120 \mu \mathrm{L}$ of dimethyl sulfoxide. The plate was read at $630 \mathrm{~nm}$ with a microplate reader. The experiment was performed three times.

\section{Quantitative real-time reverse transcriptase PCR (RT-qPCR) analysis of hut $Z_{E p}$ expression under different environmental conditions and in the fur mutant}

To examine $h u t Z_{E p}$ expression under in vitro conditions, TX01 was grown in LB medium with different $\mathrm{pH}$ values (pH 5 or 7 ) at $28{ }^{\circ} \mathrm{C}$ and incubated with or without non-immune fish serum. The bacteria were harvested by centrifugation, and total RNA was extracted with an HP Total RNA kit (Omega Bio-Tek, USA). The RNA was treated with DNase with a RNase-Free DNase Set kit (Omega Bio-Tek, USA). One microgram of total RNA was used for cDNA synthesis with Superscript II reverse transcriptase (Invitrogen, Carlsbad, CA, USA). RT-qPCR was carried out as reported previously [34]. The experiment was performed three times.

A fur mutant strain of E. piscicida was obtained in a previous study (data not published). The wild-type $E$. piscicida TX01 and fur mutant strains were cultured in LB medium to the early exponential phase. Then, bacteria were harvested, and total RNA was extracted. The expression of $h u t Z_{E p}$ in the two strains was examined by RT-qPCR as described above.

\section{Protein expression and purification}

To construct $\mathrm{pEtHutZ}$ and $\mathrm{pEtFur}$, which express HutZ $\mathrm{Z}_{\mathrm{Ep}}$ and $F u r Z_{E p}$, respectively, the sequences of $h u t Z_{E p}$ and fur $_{E p}$ were amplified by PCR with the primers HutZF5/ R5 and FurF1/R1, and the PCR products were ligated into pET32a and pET28a-SUMO, respectively. Recombinant HutZ (rHutZ) and rFur were purified as described previously [37]. Preparation of polyclonal antibodies against rHutZ and immunoblot assays were performed as previously described [37]. Protease activity analysis of rHutZ was performed as reported by Kim et al. [20]. Heminbinding activity of rHutZ was evaluated as reported by Uchida et al. [16].

Transcriptional regulation of the promoter of hut $Z_{E p}$ by Fur The speculative promoter of $h u t Z_{E p}$ (the $283 \mathrm{bp}$ of DNA upstream of the hutWXZ operon), P283, was cloned by the primers HutPF4/HutPR4 and inserted into the SwaI site of pSC11, a promoter probe plasmid [40], which resulted in pSZ283. pSZ283 was introduced into E. coli $\mathrm{DH} 5 \alpha$ by transformation and cultured on X-Gal (5-bromo-4-chloro-3-indolyl-beta-D-galactopyranoside) plates. DH5 $\alpha / \mathrm{pSZ} 283$ was then transformed with $\mathrm{pT}$ (control) and pTFur, which expressed Fur and was constructed as described by Wang et al. [40], and cultured on X-gal plates. The transformants were subjected to a $\beta$-galactosidase assay [40]. 
An electrophoresis mobility shift assay (EMSA) was performed as reported previously [41]. Briefly, the DNA fragment of the speculative promoter was amplified by PCR and labelled with carboxyfluorescein (Sangon, China). The labelled DNA was mixed with rFur and incubated at $37^{\circ} \mathrm{C}$ for $30 \mathrm{~min}$ in $20 \mu \mathrm{L}$ of binding buffer $(1 \mathrm{M}$ Tris- $\mathrm{HCl}, \mathrm{pH}$ 8.0; $5 \mathrm{M} \mathrm{NaCl}$; $0.1 \mathrm{M} \mathrm{MgCl}_{2}$; $0.5 \mathrm{M}$ EDTA; $1 \mathrm{M} \mathrm{DTT;} 80 \%$ glycerol) with or without a negative control DNA fragment (NCD), a fragment of the pT plasmid. The samples were then separated by electrophoresis in nondenaturing $8 \%$ polyacrylamide gels. For competition assays, unlabelled DNA fragments were added into the assay buffer.

\section{Statistical analysis}

All statistical analyses were performed with SPSS 18.0 software (SPSS Inc., Chicago, IL, USA). Data were analysed with analysis of variance (ANOVA), and statistical significance was defined as $P<0.05$.

\section{Results}

\section{Characterization of the sequence of HutZ}

In a previous study of $E$. piscicida, we constructed a fur mutant strain, which exhibited much higher virulence than the wild-type E. piscicida strain TX01 (data not shown). Proteomic analysis showed that the expression of a protein

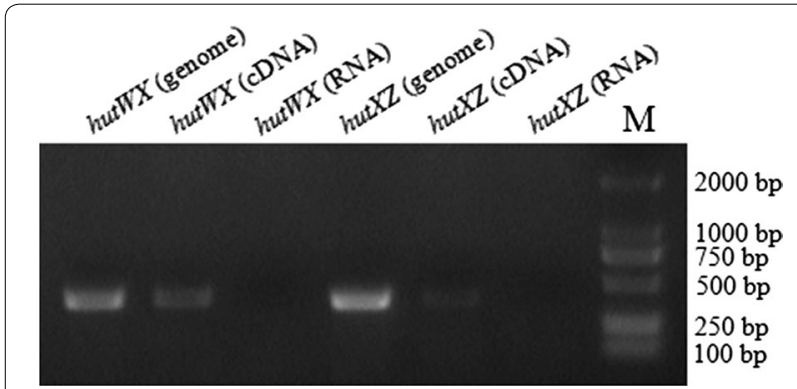

Figure 1 The genes hut $W_{E p^{\prime}}$, hut $X_{E p^{\prime}}$ and hut $Z_{E p}$ are

co-transcribed. Total RNA was isolated from Edwardsiella piscicida TX01 at a turbidity of 1.0 at $600 \mathrm{~nm}$ and treated with DNase I. CDNA was synthesized and used as the template in PCR. PCR products were amplified with specific primers for hutW $W_{E p}$ and hutX $X_{E p}$, hut $X_{E p}$ and hut $Z_{E p}$. Genomic DNA was used as a positive control, and total RNA was used as a negative control. M indicates a DNA ladder. annotated as an epimerase was significantly upregulated in the fur mutant strain compared to that in the wild-type strain (data not shown). Bioinformatics analysis showed that the epimerase may be part of an operon with two other proteins. To confirm this hypothesis, RT-PCR was performed, and the results showed that the three genes were co-transcribed (Figure 1). The first two proteins are homologues of the haem anaerobic degradation radical SAM methyltransferase ChuW/HutW and the haem utilization cytosolic carrier protein ChuX/HutX, respectively. In E. coli, the Chu operon consists of chuS, chuW, chuX, chuY, chuU, and $h m u V$ [21]. In $V$. cholerae, the Hut operon contains only three genes, hutW, hutX, and hutZ [17]. Similar to the latter, in E. piscicida, the corresponding operon comprises only three genes. Therefore, we named the third protein epimerase HutZ, and the operon was named HutWXZ (Figure 2). HutZ $_{\text {Ep }}$ shares moderate homology (50\% identity) with $E$. coli ChuY. However, multiple conserved amino acids in ChuY and its homologues did not appear in HutZ $Z_{\mathrm{Ep}}$, including some important residues buried within the ChuY dimer interface [42], such as Glu94, Gln126, Thr132, Ser136, and Thr140 (Additional file 1). Furthermore, the spatial structure of HutZ $Z_{\mathrm{Ep}}$ is also different from that of ChuY (Additional file 1); for example, seven $\alpha$-helices exist in $\mathrm{HutZ}_{\mathrm{Ep}}$, but only six $\alpha$-helices exist in ChuY [20].

To determine the function of $H u t Z_{E p}$, the coding sequences of $h u t Z_{E p}$ were expressed in and purified from E. coli. SDS-PAGE analysis showed that the purified protein exhibited a molecular mass comparable to that predicted for rHutZ $(\sim 48 \mathrm{kDa})$, and the purified protein was confirmed by western immunoblot analysis (Figure 3 ). Protease activity analysis based on the $A_{340}$ showed that rHutZ had no obvious flavin reductase activity (data not shown). Based on UV-Vis spectroscopy, we examined the hemin-binding activity of $\mathrm{rHutZ}_{\mathrm{Ep}}$, and the results showed that rHutZ $_{\mathrm{Ep}}$ did not exhibit obvious heminbinding activity (data not shown). These results suggested that HutZ $Z_{\mathrm{Ep}}$ is probably not related to hemin utilization.

\section{Construction of an E. piscicida hutZ mutant}

To examine its functional importance, the hutZ gene of $E$. piscicida TX01 was knocked out by markerless in-frame

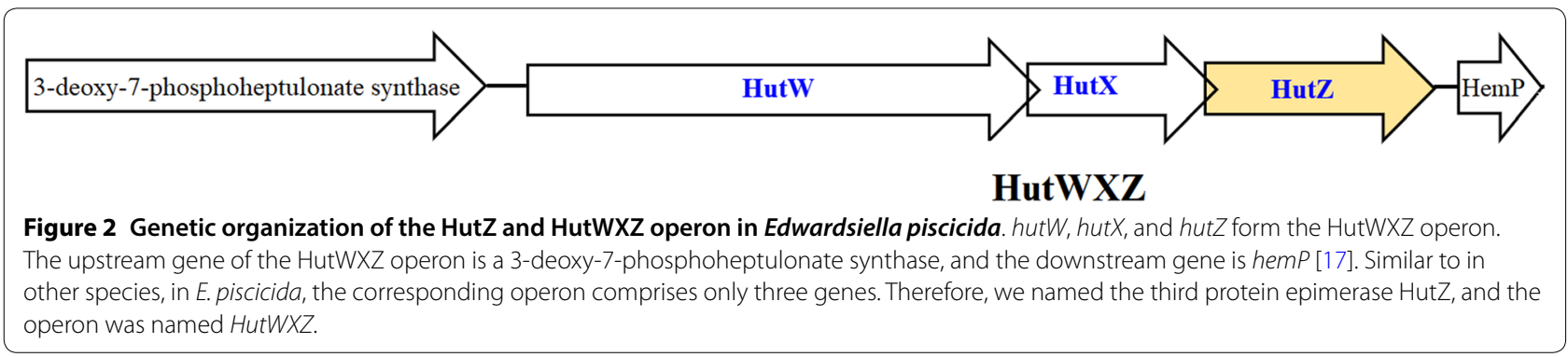






B

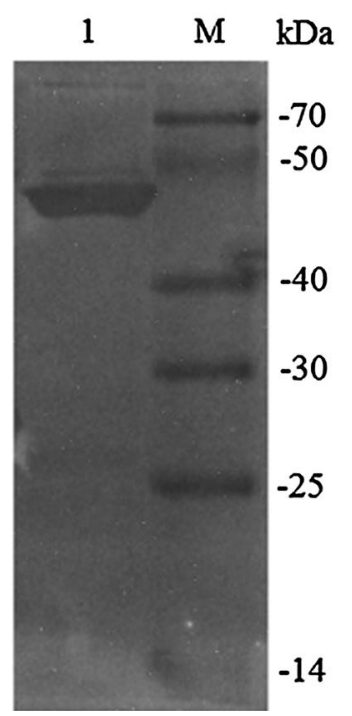

C

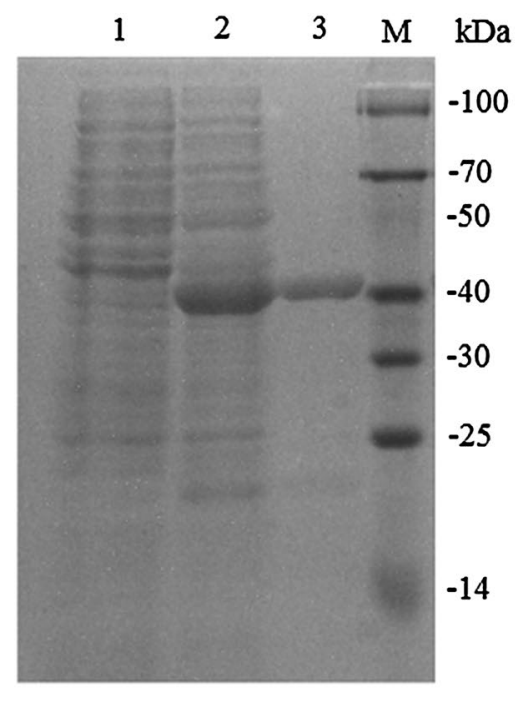

Figure 3 SDS-PAGE analysis of recombinant HutZ and rFur. A Whole-cell proteins were prepared from E. coli BL21(DE3)/pEtHutZ cultured in LB medium before (lane 1) and after (lane 2) IPTG induction. Lane 3, recombinant SoFer 1 after purification by affinity chromatography. B Western immunoblot analysis of purified rHutZ. C Expression and purification of rFur.

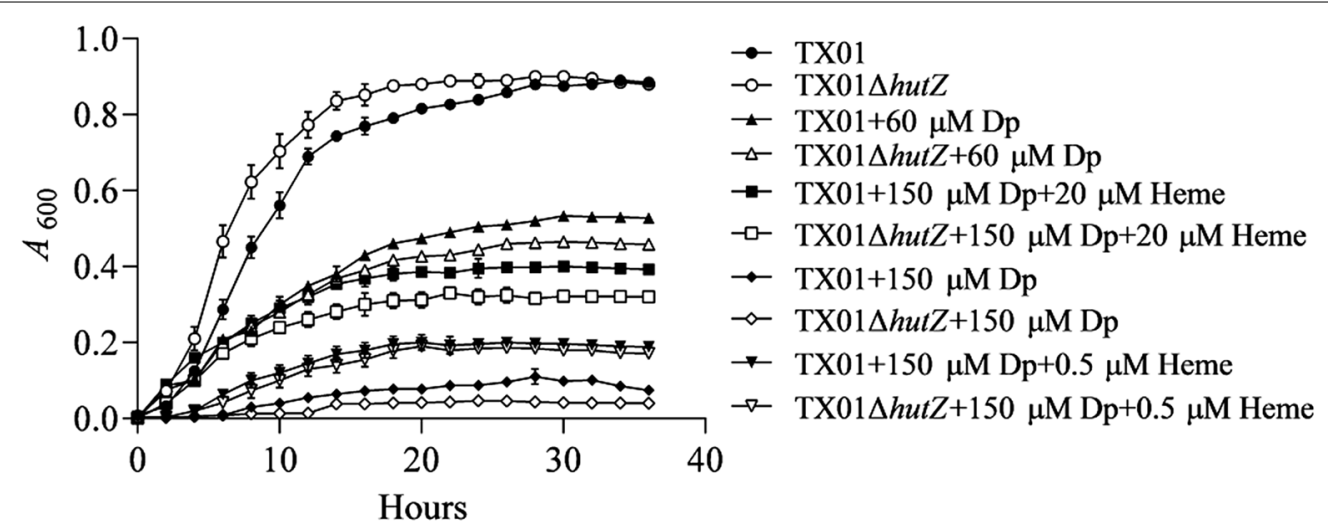

Figure 4 Growth analysis of TX01 and TX01 $\Delta$ hutZ. TX01 and TX01 $\triangle$ hutZ were cultured in LB medium, in LB medium supplemented with 2,2'dipyridyl (Dp), or in LB medium with Dp and haem, and the cell density was measured at different time points by determining the absorbance at $\mathrm{OD}_{600}$. Data are presented as the means $\pm \operatorname{SEMs}(N=3)$.

deletion of the region encoding the amino acid residues 13 to 453 . The resulting mutant was named TX01 $\Delta h u t Z$.

\section{Hut $Z_{E p}$ is not required for iron acquisition and haem utilization}

Growth analysis showed that when cultured in LB medium, TX01 $\Delta$ hut $Z$ exhibited a slightly faster generation time than TX01 at the logarithmic phase but reached cell densities similar to those of TX01 at the stationary phase (Figure 4). When cultured under conditions of iron depletion (with $60 \mu \mathrm{M} \mathrm{Dp}$ ), the growth of both TX01 $\Delta h u t Z$ and TX01 was retarded and exhibited a similar growth rate, although TX01 $\Delta$ hutZ displayed a slightly slower growth rate than TX01. When the concentration of Dp was increased to $150 \mu \mathrm{M}$, both TX01 $\Delta h u t Z$ and TX01 were barely able to grow (Figure 4). To determine the expression of $h u t Z_{E p}$ under normal conditions (i.e., cultured in LB medium) and iron deficiency conditions (i.e., cultured in LB medium with $100 \mu \mathrm{M}$ Dp), RTqPCR was performed, and the results showed that the expression of $h u t Z_{E p}$ remained unchanged when bacteria faced iron deficiency compared to the expression of $h u t Z_{E p}$ under normal conditions (data not shown). To examine whether hut $Z_{E p}$ is a key factor involved in haem 

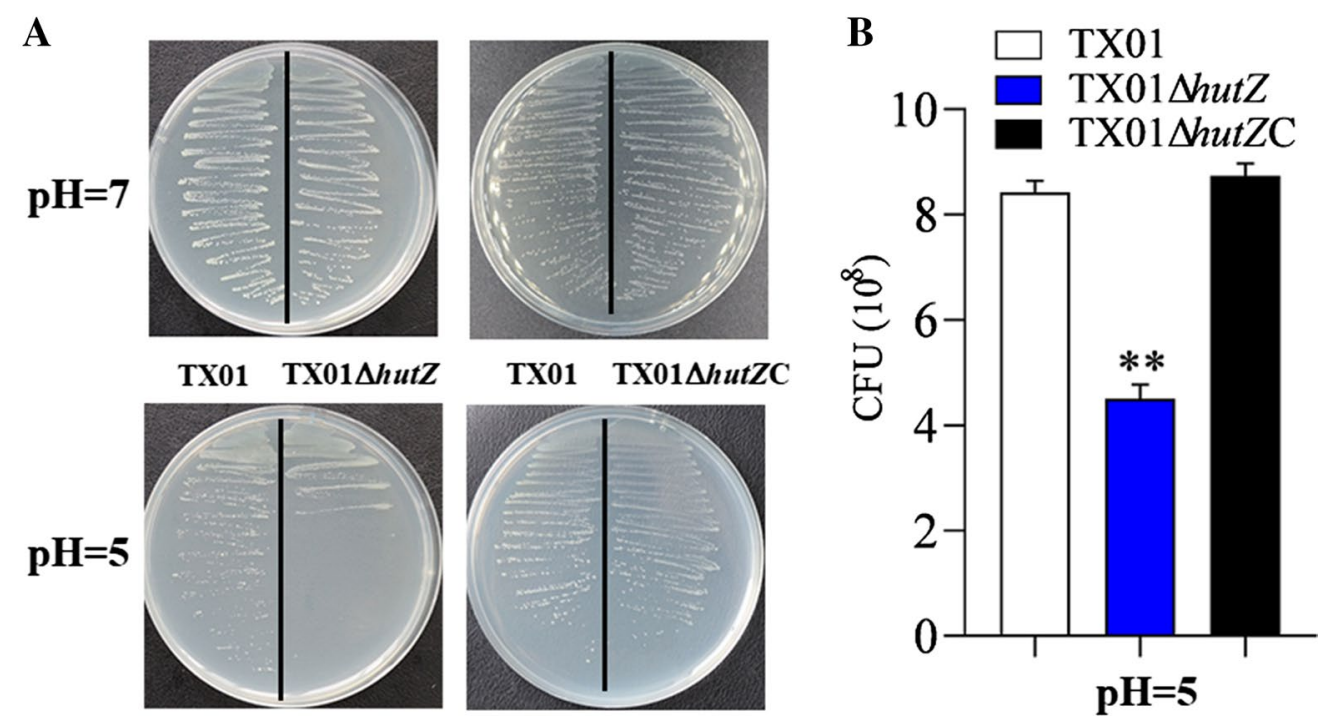

Figure 5 Sensitivity of Edwardsiella piscicida to acid stress. A TX01, TX01 $\triangle$ hutZ, and TX01 $\triangle$ hutZC were cultured in LB medium and on LB agar plates at $\mathrm{pH}=7$ and $\mathrm{pH}=5$ at $28^{\circ} \mathrm{C}$ for $24-48 \mathrm{~h}$. B Bacteria cultured to logarithmic stage were transferred to $\mathrm{LB}$ medium at $\mathrm{pH}=5$, and the populations of cultivated bacteria were counted by dilution plating. Data are the means of three independent experiments and are presented as the means $\pm \operatorname{SEMs}(N=3)$. $N$, the number of times the experiment was performed. ${ }^{* *} P<0.01$.

utilization, strains were grown in iron deficiency medium (with $150 \mu \mathrm{M}$ Dp) supplemented with a low concentration of haem $(0.5 \mu \mathrm{M})$ or high concentration of haem $(20 \mu \mathrm{M})$, and strain growth was surveyed. The results showed that with the increase in haem concentration, growth of both TX01 4 hutZ and TX01 was improved and exhibited a similar trend with no significant difference (Figure 4). These results, combined with the aforementioned results, showed that $\mathrm{HutZ}_{\mathrm{Ep}}$ is not required for iron acquirement and haem utilization.

\section{Effect of $h u t Z_{E p}$ mutation on bacterial resistance against acid stress}

Since the fur mutant caused an increase in the virulence of E. piscicida and enhanced the expression of $h u t Z_{E p}$, we speculated that $\mathrm{Hut}_{\mathrm{Ep}}$ participated in the stress resistance and pathogenicity of E. piscicida and detected the acid tolerance of the TX01 $\Delta$ hutZ mutant. Growth analysis showed that when cultured on LB agar medium, TX01 $\Delta u t Z$ and TX01 exhibited a comparable growth rate, in line with the result in LB medium. When cultured under acidic conditions, TX01 $\Delta h u t Z$ grew more poorly than TX01, and the survival of TX01 $\Delta h u t Z$ was significantly lower than that of TX01 (Figure 5). hut $Z_{E p}$ expression was analysed under normal conditions and acid stress by RT-qPCR, and the results showed that the expression of $h u t Z_{E p}$ was unchanged when bacteria faced acid stress compared to the expression of $h u t Z_{E p}$ under normal conditions (data not shown).

\section{Effect on bacterial resistance to non-immune fish serum}

To examine whether the $h u t Z_{E p}$ mutation affected serum tolerance, TX01 and TX01 $\Delta$ hutZ were incubated with non-immune flounder serum for $1 \mathrm{~h}$, and the survival of bacteria was determined by plate counting. The results showed that TX01 exhibited apparent serum resistance, as $77 \%$ of cells survived after incubation with flounder serum. However, only $57.3 \%$ of TX01 $\Delta h u t Z$ cells survived after serum treatment, which was significantly lower than that for TX01 (Figure 6A). The expression of $h u t Z_{E p}$ was also analysed under normal conditions and serum stress by RT-qPCR, and the result showed that the expression of $h u t Z_{E p}$ was significantly enhanced when bacteria faced serum stress compared to the expression of $h u t Z_{E p}$ under normal conditions (Figure 6B).

\section{Effect of hutZ $Z_{E p}$ mutation on biofilm formation and motility} Next, we surveyed whether HutZ has any relation with biofilm formation. TX01 and TX01 $\Delta h u t Z$ were cultured in polystyrene plates. After treating with Bouin fixative and crystal violet, biofilm formation was assayed. The results showed that the biofilm growth of TX01 was significantly slower than that of TX01 and was comparable to that of the control (LB medium without bacteria) (Figure 7A). Meanwhile, we surveyed the two strains' biofilm growth on YESCA agar, and the results showed that the biofilm formation capability of TX01 $\Delta h u t Z$ was markedly weaker than that of TX01 (Figure 7B). We next acquired images of the biofilms of the strains TX01 and 

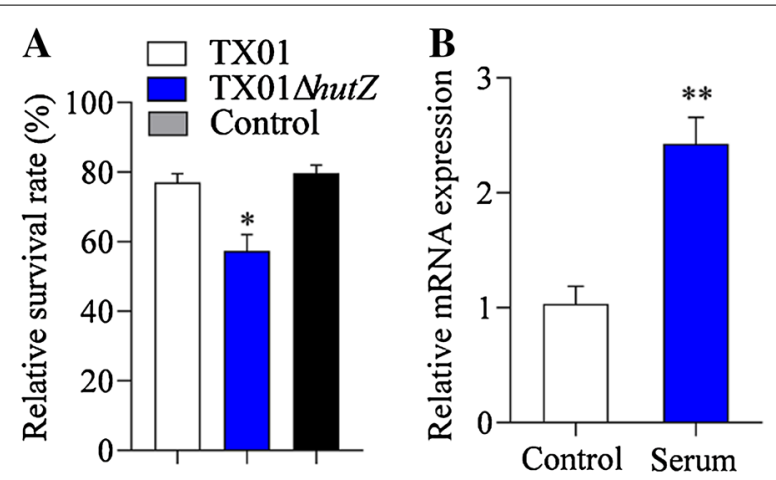

Figure 6 Effects of hut $Z_{E p}$ mutation on resistance to serum and hut $Z_{E p}$ expression under serum tolerance. A Survival of E. piscicida in fish serum. TX01, TX01 $\triangle$ hutZ, and TX01 $\triangle$ hutZC were incubated with non-immune flounder serum or PBS (control). After incubation, the survival of the bacteria was determined by plate counting. B RT-qPCR was performed with total RNA extracted from cultured Edwardsiella piscicida incubated in LB medium and incubated in flounder serum. Data are presented as the means $\pm \operatorname{SEMs}(N=3)$. $\mathrm{N}$, the number of times the experiment was performed. ${ }^{*} P<0.05$; ${ }^{* *} P<0.01$

TX01 $\Delta h u t Z$ using confocal laser scanning microscopy (CLSM). The results showed that deletion of hut $Z_{E p}$ led to a substantial decrease in the thickness and density of the biofilm during biofilm formation compared to those of the parental strain (Figure 7C). To explore whether $h u t Z_{E p}$ was directly related to E. piscicida biofilm formation, the expression of several biofilm-related genes, such as $b s m A, b s s S, h m s P$, and $\operatorname{csg} D$ [43], was investigated by RT-qPCR, and the results showed that the expression of these biofilm-related genes remained unchanged when hut $Z_{E p}$ was deleted (data not shown). These findings indicated that HutZ $Z_{\mathrm{Ep}}$ directly participates in biofilm growth and is probably a novel biofilm-related factor.

To investigate whether deletion of $h u t Z_{E p}$ has any effect on bacterial motility, TX01 and TX01 $\Delta h u t Z$ were dripped on soft LB agar plates. After culturing for $24 \mathrm{~h}$, the mobility was examined, and the results showed that the motility zone diameter of TX01 $\Delta h u t Z$ was smaller (average diameter $25 \pm 1.2 \mathrm{~mm}$ ) than that of TX01 (average diameter $33 \pm 1 \mathrm{~mm}$ ) (Figure 8). These findings indicated that $h u t Z_{E p}$ played an essential role in biofilm formation and motility.

\section{Effect of hut $Z_{E p}$ mutation on pathogenicity}

Since deletion of hut $Z_{E p}$ has an effect on bacterial resistance to serum and biofilm formation and the physiological role of $h u t Z_{E p}$ has not yet been identified, we assessed the role of $h u t Z_{E p}$ in E. piscicida pathogenesis in in vitro and in vivo infection experiments. To examine whether HutZ $Z_{\mathrm{Ep}}$ played any role in interaction with host cells, cultured FG cells were incubated with TX01 or TX01 $h$ hutZ, and the bacterial cells associated with the host cells were enumerated. The results showed that the amount of TX01 $\Delta h u t Z$ recovered from the entire (i.e., from the surface and the intracellular milieu) FG cell culture was significantly lower than that of TX01 after infecting for $1 \mathrm{~h}$ and $2 \mathrm{~h}$ (Figure 9A). It is known that E. piscicida is able to survive and replicate in host cells [29]. To examine whether the hut $Z_{E p}$ mutation played any role in the intracellular survival of TX01, FG cells were incubated with E. piscicida, and extracellular bacteria were killed. The cells were then incubated further for various amounts of time, and the number of intracellular bacteria was determined by plate counting. The results showed that the number of intracellular TX01 $\Delta h u t Z$ recovered from the cells was significantly lower than that of TX01 at various time points (Figure 9B). Hence, the $h u t Z_{E p}$ mutation significantly impaired the ability of E. piscicida to adhere to and invade host cells. To examine the effect of the $h u t Z_{E p}$ mutation on tissue infectivity, flounder were infected with the same dose of TX01 or TX01 $\Delta u t Z$, and bacterial recovery from the spleen and kidney was determined at 24 and $48 \mathrm{hpi}$. The results showed that bacterial recovery from TX01 $h u t Z$-infected fish was significantly lower than that from TX01-infected fish at $24 \mathrm{hpi}$ and $48 \mathrm{hpi}$ (Figure 10).

\section{Effect of $h u t Z_{E p}$ mutation on resistance against the immune response of host macrophages}

Since TX01 $\Delta$ hut $Z$ exhibited attenuated infectivity in the host, we wanted to examine whether the $h u t Z_{E p}$ mutation affected the ability of E. piscicida to block the activation of host phagocytes. For this purpose, flounder HK macrophages were infected with TX01 or TX01 4 hutZ, and the cellular production of ROS was determined. The results showed that ROS levels in TX01 $\Delta$ hutZ-infected cells were significantly higher than those in TX01infected cells (Figure 11).

\section{Genetic complementation of the hut $Z_{E p}$ deletion and its effect on virulence}

To examine whether the stress resistance and virulence defect observed for TX01 $\Delta h u t Z$ were indeed due to the $h u t Z_{E p}$ deletion, the strain TX01 $\triangle h u t Z C$ was created, which is a genetic variant of TX01 $\Delta h u t Z$ that expresses $h u t Z_{E p}$ in trans from a plasmid. In contrast to TX01 $4 h u t Z$, TX01 $\Delta h u t Z C$ exhibited a comparable resistance against acid stress and non-immune fish serum to those of TX01 (Figures 5 and 6). Following infection of flounder HK macrophages, TX01 $4 h u t Z C$-induced production of ROS was similar to that induced by TX01 infection (Figure 11). Likewise, the bacterial dissemination capacity of TX01 $4 h u t Z C$ in fish tissues was comparable to that of TX01 (Figure 10). 


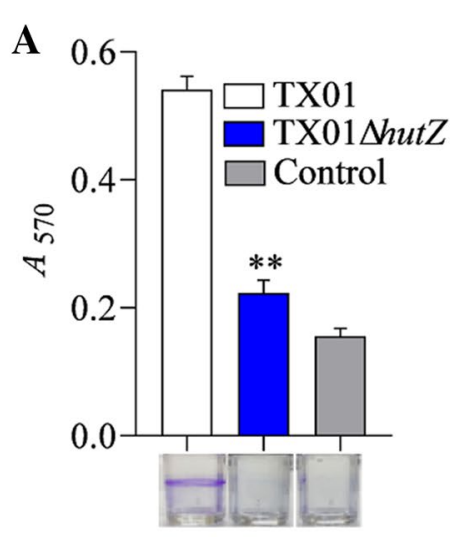

B

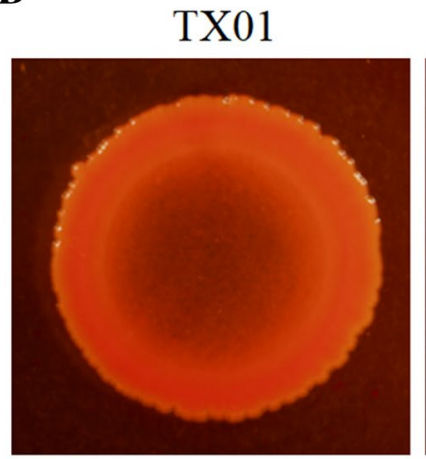

TX01 $4 h u t Z$

C

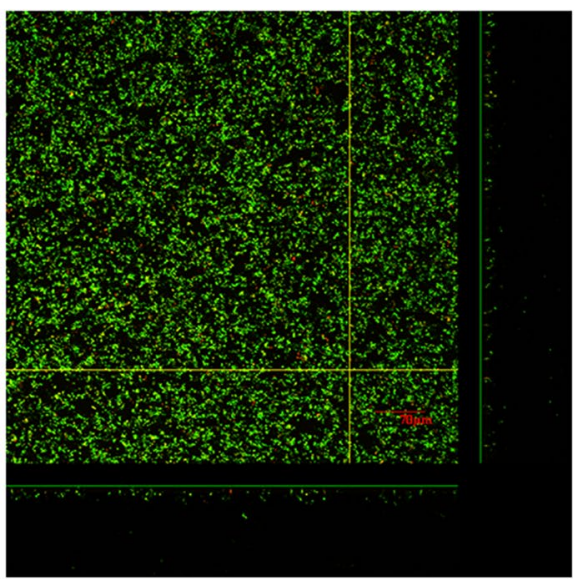

TX01

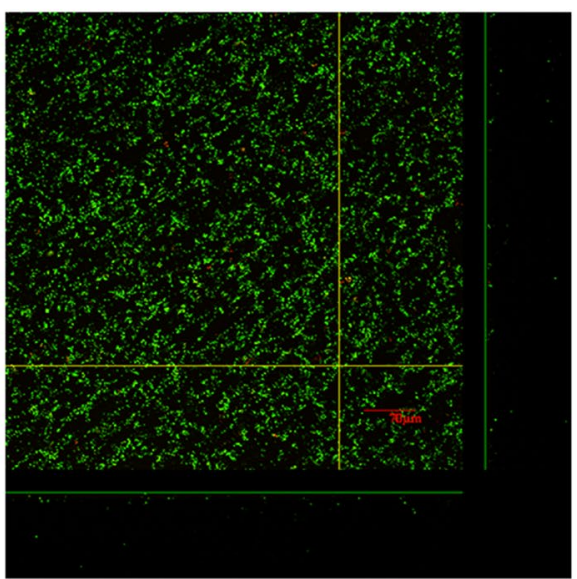

TX01 $h u t Z$

Figure 7 Effects of hutZ $Z_{E p}$ mutation on biofilm growth. A Biofilm-forming capacity of E. piscicida. TX01 and TX01 $\triangle$ hutZ were incubated in polystyrene plates, and biofilm formation was determined by measuring the $A_{570}$ of the final eluates. B The viability of biofilm growth of $E$. piscicida as determined by confocal laser scanning microscopy (CLSM). Cells in the biofilms were stained with a BacLight LIVE/DEAD kit to reveal viable (green fluorescence) and non-viable (red fluorescence) bacteria. Data are presented as the means $\pm \mathrm{SEMs}(N=3)$. N, the number of times the experiment was performed. ${ }^{* *} P<0.01$.

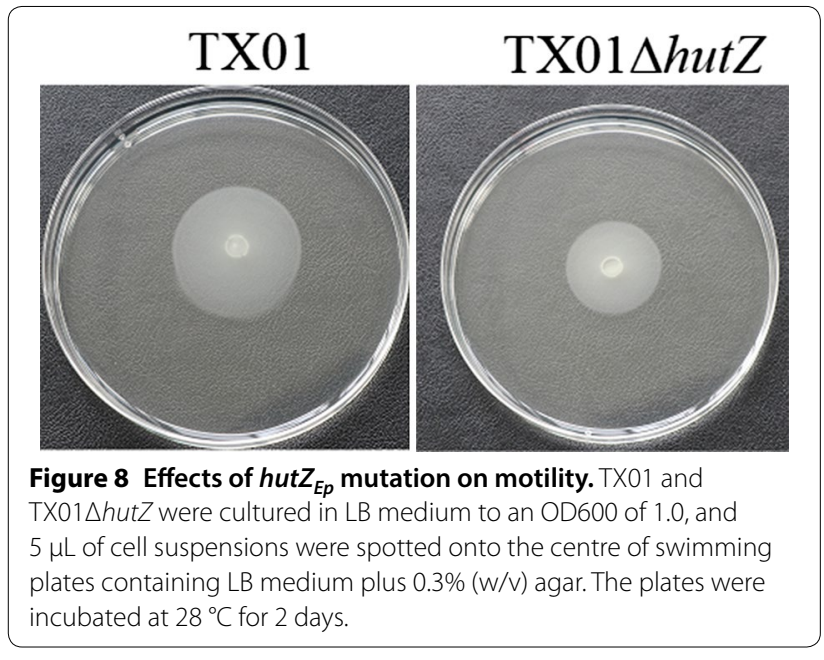

\section{Expression of hut $Z_{E p}$ is regulated by Fur (ferric uptake} regulator)

As mentioned above, HutZ expression was significantly upregulated in the fur mutant strain by proteomic analysis, so we detected the expression of $h u t Z_{E p}$ at the mRNA and protein levels. RT-qPCR showed that the expression of $h u t Z_{E p}$ in the fur mutant strain was 145fold higher than that of $h u t Z_{E p}$ in the wild-type strain (Figure 12A). Western blotting showed that the expression of HutZ $Z_{\mathrm{Ep}}$ in the fur mutant was also significantly higher than that of HutZ $Z_{\mathrm{Ep}}$ in the wild-type strain (Figure 12C). To detect the regulatory effect of Fur on the promoter activity of $h u t Z_{E p}$, the speculative promoter of $h u t Z_{E p}$, P283, was cloned into the promoter probe plasmid pSC11, resulting in $\mathrm{DH} 5 \alpha / \mathrm{pSZ} 283$. When DH5 $\alpha /$ pSZ283 was cultured on LB agar plates with 

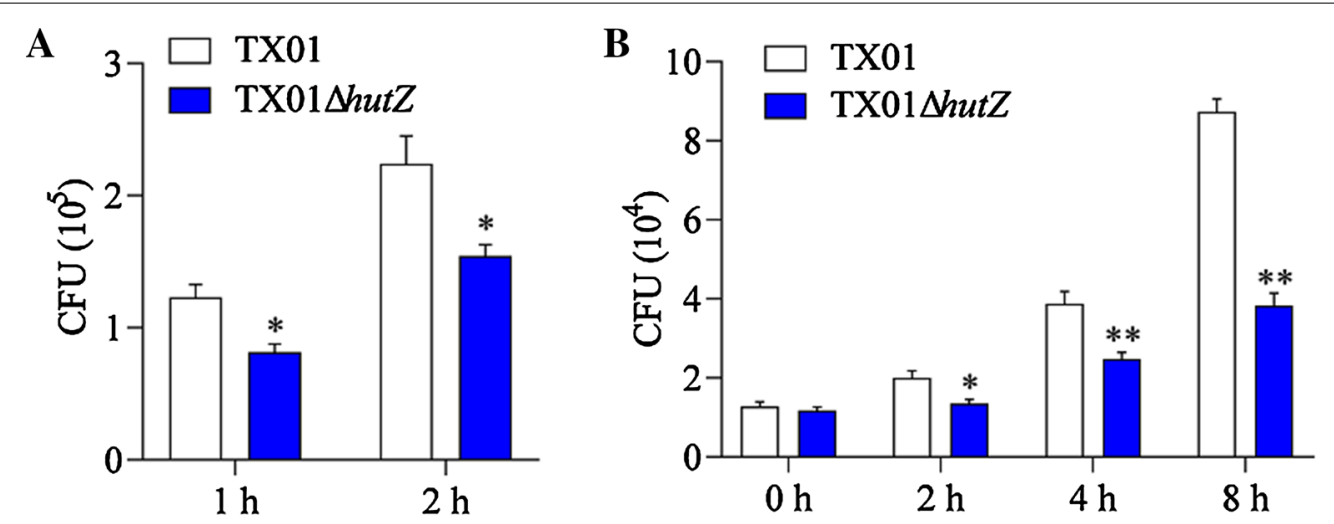

Figure 9 Effect of hutZ $Z_{E p}$ mutation on cellular infection and replication. A Edwardsiella piscicida invasion of flounder gill cells (FG cells). FG cells were infected with the same dose of TX01 and TX01 $\triangle$ hutZ for various amounts of time and washed with PBS. Then, FG cells were lysed, and the bacteria associated with and invaded into the host cells were enumerated. B Replication of E. piscicida in FG cells. After infecting with TX01 and TX01 $\triangle$ hutZ for $2 \mathrm{~h}$, FG cells were treated with gentamicin for $2 \mathrm{~h}$. The cells were then incubated further for various amounts of time, and the number of intracellular bacteria was determined by plate counting. Data are the means of three independent experiments and are presented as the means $\pm \operatorname{SEMs}(N=3)$. $N$, the number of times the experiment was performed. ${ }^{*} P<0.05$, ${ }^{*} P<0.01$.

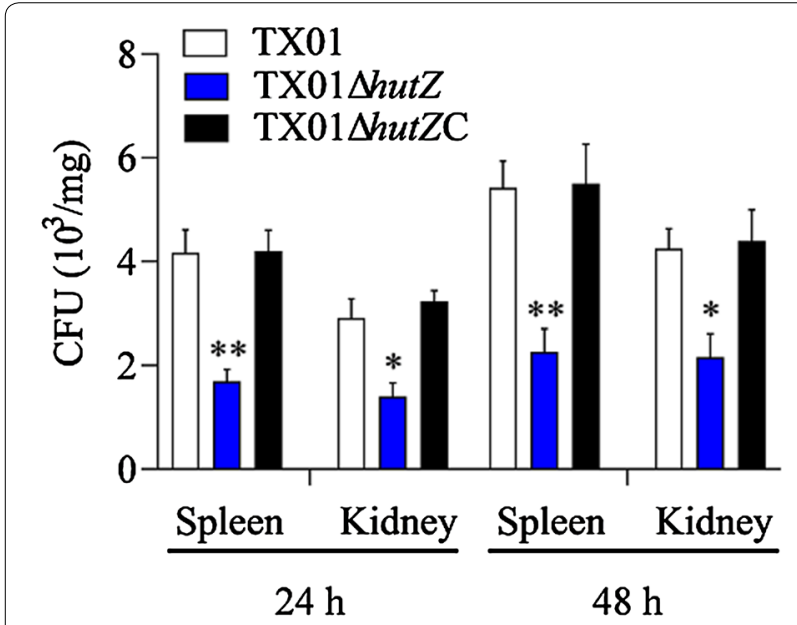

Figure 10 Bacterial dissemination in fish tissues. Flounders were infected with the same dose of TX01, TX01 $\triangle$ hutZ, or TX01 $\triangle$ hutZC, and bacterial recovery from the spleen and kidney was determined by plate counting at $24 \mathrm{~h}$ and $48 \mathrm{hpi}$. Data are presented as the means $\pm \operatorname{SEMs}(N=3)$. $N$, the number of times the experiment was performed. ${ }^{*} P<0.05,{ }^{* *} P<0.01$.

$\mathrm{X}$-gal, the bacterial colonies were blue, which indicated that P283 has promoter activity. DH5 $/$ pSZ283 was then transformed with pTFur (expresses Fur) and pT (control). On an X-gal plate, the blue of DH5 $\alpha / \mathrm{pSZ283/}$ pTFur was obviously weak compared with that of DH5 $\alpha /$ pSZ283/pT (Figure 12B). $\beta$-galactosidase assays showed that Miller units produced by DH5 $\alpha / \mathrm{pSZ} 283 /$ pTFur $(2.11 \pm 0.15)$ were significantly lower than those produced by DH5 $\alpha / \mathrm{pSZ} 283 / \mathrm{pT}(201.12 \pm 0.10)$. These results indicated that Fur negatively regulated the transcription of $h u t Z_{E p}$. To further analyse the function of

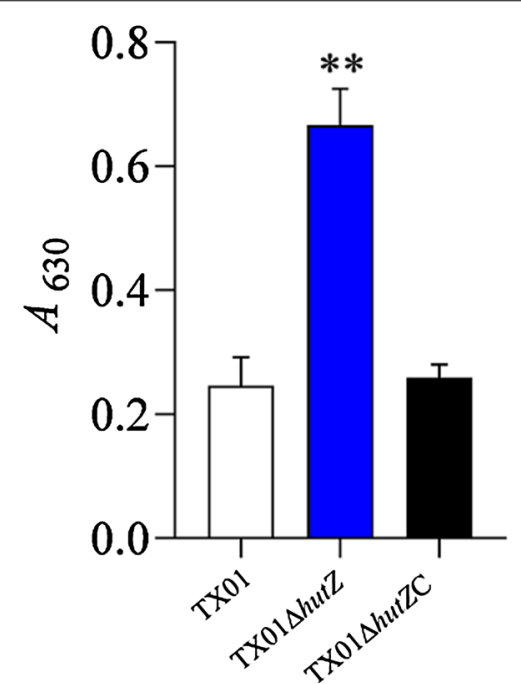

Figure 11 Effect of hutZ $Z_{E p}$ mutation on the immune response of macrophages. Flounder head kidney macrophages were infected with TX01, TX01 $\triangle$ hutZ, or TX01 $\triangle$ hutZC, and reactive oxygen species production in the cells was determined at $2 \mathrm{hpi}$. Data are presented as the means \pm SEMs $(N=3) .{ }^{*} P<0.01$.

Fur, rFur was expressed and purified from E. coli (Figure 3). An electrophoresis mobility shift assay (EMSA) showed that the purified rFur could bind the speculative promoter P283 (Figure 12D), which indicated that HutZ is directly regulated by Fur.

\section{Discussion}

Haem utilization systems play important roles in bacterial iron acquisition, adversity adaptation and pathogenicity. To date, there are no reports about haem 
A

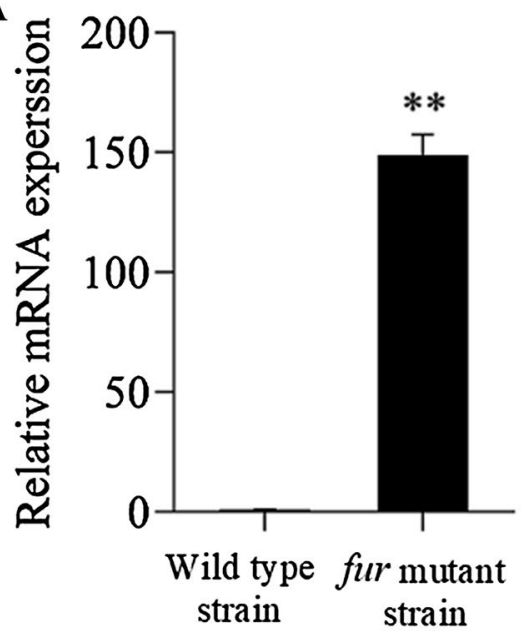

C

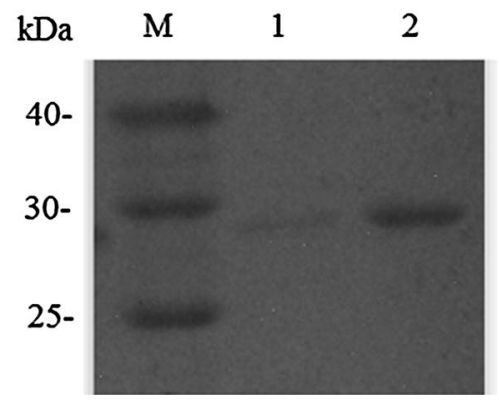

B

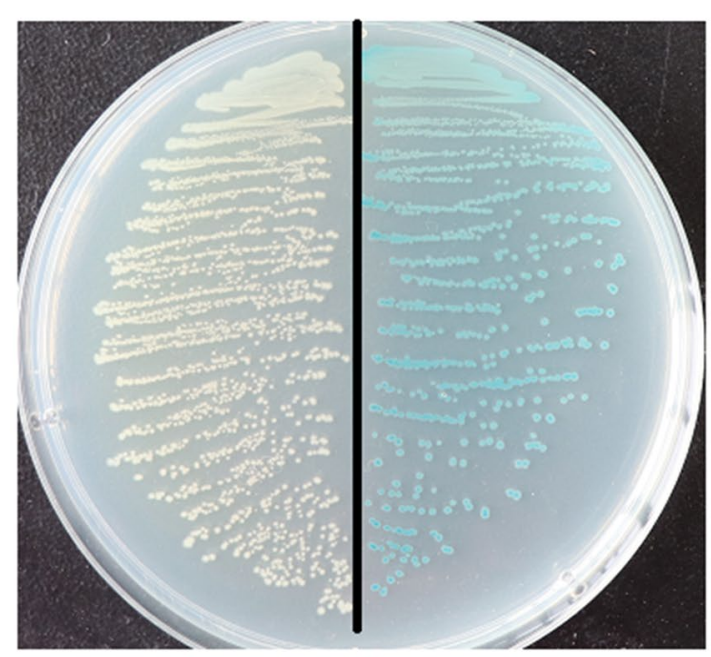

D

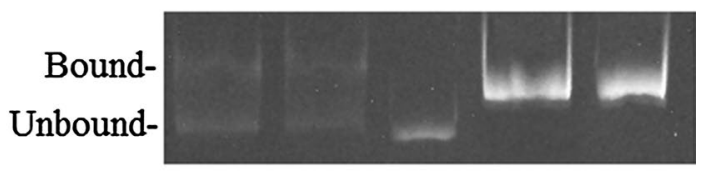

Fur

$\begin{array}{rrrrrr}\text { Labeled P283 } & + & + & + & - & - \\ \text { Unlabeled P283 } & - & + & - & - & - \\ \text { Labeled NCD } & - & - & - & + & +\end{array}$

Figure 12 Expression of $h u t Z_{E p}$ is regulated by Fur. A RT-qPCR was performed with total RNA extracted from wild-type TX01 and a fur mutant strain cultured in normal LB medium. The expression level of hut $Z_{E p}$ in the wild-type TX01 strain was set at 1. B DH5a/pSZ283/pTFur and DH5a/ pSZ283/pT were streaked and cultured on LB plates with X-gal, kanamycin, and ampicillin. C The expression of HutZ was examined by Western blot. 1. the expression of HutZ in wild type TX01; 2. the expression of HutZ in fur mutant strain. $\mathbf{D}$ Interaction between Fur and the speculative promoter regions of hut $Z_{E p}$. An electrophoresis mobility shift assay (EMSA) was performed in binding buffer containing Fur, unlabelled or carboxyfluorescein-labelled negative control DNA (NCD), and carboxyfluorescein-labelled D333. The negative control DNA (NCD) was derived from a fragment of the pT plasmid. Data are presented as the means \pm SEMs $(N=3)$. N, the number of times the experiment was performed. ${ }^{* *} P<0.01$.

utilization in E. piscicida. In this study, a speculative haem utilization protein, HutZ $Z_{\mathrm{Ep}}$, was characterized in E. piscicida. HutZ $Z_{\mathrm{Ep}}$ is encoded along with two other proteins. The first two other proteins were annotated as haem anaerobic degradation radical SAM methyltransferase ChuW/HutW and haem utilization cytosolic carrier protein ChuX/HutX, respectively, in the genome [32]. In $E$. coli, the chu gene cluster contains several genes, such as chuS, chuW, chuX, chuY, chuU, and $h m u V$, which form an operon and are involved in haem/iron acquisition and homeostasis. [21]. A similar operon also exists in Shigella dysenteriae [44]. However, in $V$. cholerae, the haem utilization operon contains only three genes, hutW, hutX, and hutZ [17]. Similarly, the hugWXZ operon was found in P. shigelloides [18]. In E. piscicida, we named the third gene $h u t Z_{E p}$, and the operon was called hut $W X Z_{E p}$.

Since $E$. piscicida is a member of Enterobacteriales, we wanted to determine whether $\mathrm{HutZ}_{\mathrm{Ep}}$ has a function similar to that of ChuY. ChuY catalyses FMN reduction using NADPH or NADH as the electron donor, and ChuY also possesses hemin-binding activity [20]. However, unlike ChuY, we did not find that rHutZ exhibited obvious flavin reductase activity and heminbinding activity, which suggested that $\mathrm{HutZ}_{\mathrm{Ep}}$ is probably not related to hemin utilization. Differences in operon composition, conserved residues, and structure perhaps lead to differences in functionality between 
HutZ $Z_{\mathrm{Ep}}$ and ChuY. Moreover, deletion of hut $Z_{E p}$ had no significant effect on the growth of E. piscicida under iron deficiency conditions. It has been reported that HutZ in V. cholerae is a cytoplasmic haem-binding protein and is required for efficient haem degradation or haem utilization $[15,16,45,46]$. HugZ from P. shigelloides was needed for survival when haem was used as an iron source [18]. However, our results showed that $h u t Z_{E p}$ is not involved in haem utilization. These results, combined with the aforementioned results, showed that $\mathrm{Hut}_{\mathrm{Ep}}$ is not required for iron acquisition and haem utilization.

Since HutZ $_{\mathrm{Ep}}$ is irrelevant to iron acquisition, we wanted to determine whether it possesses other functions, especially adversity resistance and pathogenicity functions. Acid tolerance is an important trait for various pathogens during infection and is regulated by the regulator Fur in a variety of pathogens, such as Salmonella typhimurium, E. coli, and Aeromonas salmonicida [47-49]. We found that the deletion of $h u t Z_{E p}$ markedly attenuated the acid tolerance capability of E. piscicida. For E. piscicida, evasion of serum-mediated bactericidal activity is a characteristic phenotype, but the mechanism is still poorly understood. It has been reported that E. piscicida evades serum killing by preventing complement activation via the alternative pathway [50]. Chen et al. [28] found that E. piscicida tunes the tricarboxylic acid cycle to evade complement-mediated killing, which reveals a previously unknown membrane potentialdependent mechanism of serum resistance. Two novel serum-induced proteins, Sip1 and Sip2, were found to be essential to serum resistance, which are also different from known mechanisms $[29,51]$. Other virulence factors involved in resistance against the bactericidal effect of hos serum include the serine protease autotransporter Tsh, lysozyme inhibitor Ivy, and thioredoxin TrxH $[34,39,52]$. In this study, deletion of $h u t Z_{E p}$ decreased the resistance of $E$. piscicida against host serum killing, which indicated that it is a novel virulence factor related to serum resistance. However, its mechanism requires further investigation.

Most bacteria can switch between a planktonic form and a biofilm mode, which aids in bacterial adaptation to environmental signals and stresses. Gram-negative bacteria, such as E. coli, form biofilms that consist of a bacterial colony embedded in a matrix of extracellular polymeric substances that protect the microbes from adverse environmental conditions and result in infection [53]. In E. piscicida, a number of virulence factors have been found to be relevant to biofilm formation. Among these factors, some inhibit biofilm formation. For example, the type III translocon protein $\mathrm{EseC}$ inhibits biofilm formation by sequestering the regulator EseE [54], and an rpoS sigma factor mutant displayed markedly increased biofilm formation [55]. Deletion of the ugd gene, which encodes UDP-glucose dehydrogenase, enhanced autoaggregation and biofilm formation [56]. However, additional genes are essential for biofilm formation by $E$. piscicida. EseB is a prerequisite for autoaggregation and biofilm formation [57]. Deficiency in multiple genes, such as the serine protease autotransporter $t s h, r c s B$, the sigma factor rpoN, the invasin gene, the flagellar genes $\mathrm{fliC}$, $f l h D C$, and the quorum sensing-related gene $l u x S$, results in markedly decreased biofilm formation [33, 34, 58-62]. In the current study, the biofilm formation ability of the hut $Z_{E p}$ mutant strain TX01 $\Delta$ hut $Z$ was markedly weaker than that of the wild-type strain TX01. The expression of some known biofilm-related genes was not affected by $h u t Z_{E p}$. These findings indicated that $\mathrm{HutZ}_{\mathrm{Ep}}$ directly participates in biofilm growth and is probably a novel biofilm-related factor.

Bacterial biofilm formation is often closely related to motility. For example, RpoX plays distinct roles in stress response, motility, and biofilm formation in the marine pathogen Vibrio alginolyticus [63]. ToxR is required for the biofilm formation and motility of Vibrio parahaemolyticus [64]. Flagellar genes affect both bacterial motility and biofilm formation [61]. In accordance with these reports, our study showed that HutZ $\mathrm{E}_{\mathrm{Ep}}$ was involved in the motility of E. piscicida.

These findings clearly demonstrated that $h u t Z_{E p}$ played an essential role in adversity resistance, biofilm formation, and motility, which indicated that $h u t Z_{E p}$ was most likely involved in pathogenicity. Therefore, we examined the effect of $h u t Z_{E p}$ on E. piscicida pathogenicity. The results showed that inactivation of $h u t Z_{E p}$ significantly weakened the ability of $E$. piscicida to invade host cells. Similarly, the capability of E. piscicida to survive and replicate in host cells significantly declined when $h u t Z_{E p}$ was inactivated. Moreover, an in vivo experiment showed that TX01 $\Delta$ hutZ had a severely reduced ability to infect host tissues. In support of these results, the host immune response induced by TX01 and TX01 $\Delta h u t Z$ was examined, and the results showed that reactive oxygen species (ROS) levels in TX01 $\Delta h u t Z$-infected macrophages were significantly higher than those in TX01-infected cells. Introduction of an in trans-expressed $h u t Z_{E p}$ gene restored the lost virulence of TX01 $\Delta h u t Z$. These findings indicate that $h u t Z_{E p}$ is vital to the pathogenicity of E. piscicida.

The abovementioned results showed that $h u t Z_{E p}$ plays a role in resistance against acid stress, but the expression of $h u t Z_{E p}$ did not change under low $\mathrm{pH}$ conditions. hut $Z_{E p}$ also plays a role in resistance against 
non-immune fish serum. However, the expression of $h u t Z_{E p}$ was significantly enhanced when bacteria faced serum stress. These results suggest that there may be a complicated relation between the expression and function of $h u t Z_{E p}$. In $V$. cholerae, HutZ is required for efficient haem utilization, and its promoter region contains several potential binding sites for the iron regulatory protein Fur [16]. Moreover, the synthesis of HutZ is negatively regulated by iron [15]. Haem uptake or utilization operon is frequently regulated by Fur [65]. Fur was initially considered a regulator of genes associated with iron uptake. With in-depth research, it is clear that Fur is a global regulator and is involved in a variety of cellular processes, including stress response and virulence [66]. In our study, we confirmed that HutZ $Z_{\mathrm{Ep}}$ was directly regulated by Fur. Although HutZ was not required for iron acquisition and haem utilization, HutZ was involved in the bacterial stress response and virulence, which is in accordance with the function of Fur [66, 67].

In conclusion, this study characterized HutZ from the fish pathogen E. piscicida. Our results showed that the expression of $h u t Z_{E p}$ was upregulated by serum stress and was negatively regulated by Fur. Hut $Z_{\mathrm{Ep}}$ was not involved in iron acquisition and haem utilization but played an important role in coping with adverse circumstances and functioned as a factor that was essential to bacterial infection both at the cellular level and in a live fish model. Hut $Z_{\mathrm{Ep}}$ was also required for blocking host macrophage activation. This report is the first study of HutZ in a fish pathogen, and the results indicated that $\mathrm{HutZ}_{\mathrm{Ep}}$ is a novel virulence factor of $E$. piscicida.

\section{Supplementary information}

Supplementary information accompanies this paper at https://doi. org/10.1186/s13567-019-0693-4.

\section{Additional file 1. Multiple sequence alignment of HutZ homologues and spatial structure of HutZ. A, Sequence alignment of Edwardsiella piscicida HutZ with Escherichia coli ChuY and its homologues from other species. The percentage number in the bracket following each species name represents the overall sequence identity between $H u t Z_{\text {Ep }}$ and the specified species. The consensus residues are in dark blue, and the resi- dues that are $\geq 75 \%$ identical among the aligned sequences are in pink. The GenBank accession numbers of the aligned sequences are as follows: Edwardsiella piscicida, WP_012848635.1; Escherichia coli, AUG95424.1; Citro- bacter koseri,WP_115626451.1; and Klebsiella oxytoca, WP_142475928.1. B, The spatial structure was determined with the PyMOL Molecular Graphics System. a-Helices are shown in red.}

\section{Acknowledgements}

This work was supported by the Hainan Provincial Natural Science Foundation of China (2019CXTD413), the Central Public-interest Scientific Institution Basal Research Fund for the Chinese Academy of Tropical Agricultural Sciences (1630052018005, 19CXTD-32), the Financial Fund of the Ministry of Agriculture and Rural Affairs, P. R. of China (NFZX2018), and the National Natural Science Foundation of China (41476138).

\section{Authors' contributions}

YJS performed the experiments and analysed the data. QJF and $\mathrm{HQH}$ participated in infection expression and some data analysis. CGG and $\mathrm{YHH}$ designed the experiments. YHH wrote the paper, and CGG revised the paper. All authors read and approved the final manuscript.

\section{Ethics approval and consent to participate}

The study was approved by the ethics committee of the Institute of Tropical Bioscience and Biotechnology, Chinese Academy of Tropical Agricultural Sciences. Efforts were taken to ensure that all research animals received good care and humane treatment.

\section{Competing interests}

The authors declare that they have no competing interests.

\section{Author details}

1 Ocean College of Hebei Agricultural University, Qinhuangdao 066000, China. ${ }^{2}$ Institute of Tropical Bioscience and Biotechnology, Chinese Academy of Tropical Agricultural Sciences, Haikou 571101, China. ${ }^{3}$ Laboratory for Marine Biology and Biotechnology, Pilot National Laboratory for Marine Science and Technology, Qingdao, China. ${ }^{4}$ Hainan Provincial Key Laboratory for Functional Components Research and Utilization of Marine Bio-resources, Haikou 571101, China.

Received: 25 June 2019 Accepted: 19 August 2019

Published online: 02 October 2019

\section{References}

1. Fillat MF (2014) The FUR (ferric uptake regulator) superfamily: diversity and versatility of key transcriptional regulators. Arch Biochem Biophys $546: 41-52$

2. Lill R (2009) Function and biogenesis of iron-sulphur proteins. Nature 460:831-838

3. Schaible UE, Kaufmann SH (2004) Iron and microbial infection. Nat Rev Microbiol 2:946-953

4. Porcheron G, Garenaux A, Proulx J, Sabri M, Dozois CM (2013) Iron, copper, zinc, and manganese transport and regulation in pathogenic Enterobacteria: correlations between strains, site of infection and the relative importance of the different metal transport systems for virulence. Front Cell Infect Microbiol 3:90

5. Otto BR, Verweij-van Vught AM, MacLaren DM (1992) Transferrins and heme-compounds as iron sources for pathogenic bacteria. Crit Rev Microbiol 18:217-233

6. Kortman GA, Raffatellu M, Swinkels DW, Tjalsma H (2014) Nutritional iron turned inside out: intestinal stress from a gut microbial perspective. FEMS Microbiol Rev 38:1202-1234

7. Wilks A, Burkhard KA (2007) Heme and virulence: how bacterial pathogens regulate, transport and utilize heme. Nat Prod Rep 24:511-522

8. Genco CA, Dixon DW (2001) Emerging strategies in microbial haem capture. Mol Microbiol 39:1-11

9. Choby JE, Skaar EP (2016) Heme synthesis and acquisition in bacterial pathogens. J Mol Biol 428:3408-3428

10. Contreras H, Chim N, Credali A, Goulding CW (2014) Heme uptake in bacterial pathogens. Curr Opin Chem Biol 19:34-41

11. Río SJ, Osorio CR, Lemos ML (2005) Heme uptake genes in human and fish isolates of Photobacterium damselae: existence of hutA pseudogenes. Arch Microbiol 183:347-358

12. Reidl J, Mekalanos JJ (1996) Lipoprotein e(P4) is essential for hemin uptake by Haemophilus influenzae. J Exp Med 183:621-629

13. Smith AD, Wilks A (2015) Differential contributions of the outer membrane receptors PhuR and HasR to heme acquisition in Pseudomonas aeruginosa. J Biol Chem 290:7756-7766

14. Lewis LA, Sung MH, Gipson M, Hartman K, Dyer DW (1998) Transport of intact porphyrin by HpuAB, the hemoglobin-haptoglobin utilization system of Neisseria meningitidis. J Bacteriol 180:6043-6047

15. Wyckoff EE, Schmitt M, Wilks A, Payne SM (2004) HutZ is required for efficient heme utilization in Vibrio cholerae. J Bacteriol 186:4142-4151 
16. Uchida T, Sekine Y, Matsui T, Ikeda-Saito M, Ishimori K (2012) A heme degradation enzyme, HutZ, from Vibrio cholerae. Chem Commun (Camb) 48:6741-6743

17. Sekine Y, Tanzawa T, Tanaka Y, Ishimori K, Uchida T (2016) Cytoplasmic heme-binding protein (HutX) from Vibrio cholerae is an intracellular heme transport protein for the heme-degrading enzyme, HutZ. Biochemistry 55:884-893

18. Henderson DP, Wyckoff EE, Rashidi CE, Verlei H, Oldham AL (2001) Characterization of the Plesiomonas shigelloides genes encoding the heme iron utilization system. J Bacteriol 183:2715-2723

19. Suits MD, Lang J, Pal GP, Couture M, Jia Z (2009) Structure and heme binding properties of Escherichia coli O157:H7 ChuX. Protein Sci 18:825-838

20. Kim H, Chaurasia AK, Kim T, Choi J, Ha SC, Kim D, Kim KK (2017) Structural and functional study of ChuY from Escherichia coli strain CFT073. Biochem Biophys Res Commun 482:1176-1182

21. LaMattina JW, Nix DB, Lanzilotta WN (2016) Radical new paradigm for heme degradation in Escherichia coli O157:H7. Proc Natl Acad Sci USA 113:12138-12143

22. Abayneh T, Colquhoun DJ, Sørum H (2013) Edwardsiella piscicida sp. nov., a novel species pathogenic to fish. J Appl Microbiol 114:644-654

23. Liu Y, Zhao L, Yang M, Yin K, Zhou X, Leung KY, Liu Q, Zhang Y, Wang Q (2017) Transcriptomic dissection of the horizontally acquired response regulator EsrB reveals its global regulatory roles in the physiological adaptation and activation of T3SS and the cognate effector repertoire in Edwardsiella piscicida during infection toward turbot. Virulence 8:1355-1377

24. Mohanty BR, Sahoo PK (2007) Edwardsiellosis in fish: a brief review. J Biosci 32:1331-1344

25. Buján N, Toranzo AE, Magariños B (2018) Edwardsiella piscicida: a significant bacterial pathogen of cultured fish. Dis Aquat Organ 131:59-71

26. Yin K, Guan Y, Ma R, Wei L, Liu B, Liu X, Zhou X, Ma Y, Zhang Y, Waldor MK, Wang Q (2018) Critical role for a promoter discriminator in RpoS control of virulence in Edwardsiella piscicida. PLoS Pathog 14:e1007272

27. Sui $\mathrm{ZH}, \mathrm{Xu} \mathrm{H}$, Wang $H$, Jiang S, Chi H, Sun L (2017) Intracellular trafficking pathways of Edwardsiella tarda: from clathrin-and caveolinmediated endocytosis to endosome and lysosome. Front Cell Infect Microbiol 7:400

28. Cheng ZX, Gong QY, Wang Z, Chen ZG, Ye JZ, Li J, Wang J, Yang MJ, Ling XP, Peng B (2017) Edwardsiella tarda tunes tricarboxylic acid cycle to evade complement-mediated killing. Front Immunol 8:1706

29. Li MF, Sun L (2018) Edwardsiella tarda Sip2: a serum-induced protein that is essential to serum survival, acid resistance, intracellular replication, and host infection. Front Microbiol 9:1084

30. Yi J, Xiao SB, Zeng ZX, Lu JF, Liu LY, Laghari ZA, Nie P, Yu HB, Xie HX (2016) EseE of Edwardsiella tarda augments secretion of translocon protein EseC and expression of the escC-eseE operon. Infect Immun 84:2336-2344

31. Hu T, Zhang L, Wang W, Yang D, Xiao J, Zhang Y, Liu X, Liu Q (2019) Edwardsiella piscicida enters non-phagocytic cells via a macropinocytosisinvolved hybrid mechanism. J Bacteriol 201:e00548-18

32. Wang $Q$, Yang $M$, Xiao J, Wu H, Wang X, Lv Y, Xu L, Zheng H, Wang S, Zhao G, Liu Q, Zhang Y (2009) Genome sequence of the versatile fish pathogen Edwardsiella tarda provides insights into its adaptation to broad host ranges and intracellular niches. PLoS One 4:e7646

33. Zhang M, Sun K, Sun L (2008) Regulation of autoinducer 2 production and luxS expression in a pathogenic Edwardsiella tarda strain. Microbiology 154:2060-2069

34. Hu YH, Zhou HZ, Jin QW, Zhang J (2016) The serine protease autotransporter Tsh contributes to the virulence of Edwardsiella tarda. Vet Microbiol 189:68-74

35. Chan WT, Domenech M, Moreno-Córdoba I, Navarro-Martínez V, Nieto C, Moscoso M, García E, Espinosa M (2018) The Streptococcus pneumoniae yefM-yoeB and relBE toxin-antitoxin operons participate in oxidative stress and biofilm formation. Toxins (Basel) 10:E378

36. Hufnagel DA, Price JE, Stephenson RE, Kelley J, Benoit MF, Chapman MR (2017) Thiol starvation induces redox-mediated dysregulation of Escherichia coli biofilm components. J Bacteriol 200:e00389-17

37. Hu YH, Liu CS, Hou JH, Sun L (2009) Identification, characterization, and molecular application of a virulence-associated autotransporter from a pathogenic Pseudomonas fluorescens. Appl Environ Microbiol 75:4333-4340
38. Wang BY, Huang HQ, Li S, Tang P, Dai HF, Xian JA, Sun DM, Hu YH (2019) Thioredoxin $\mathrm{H}$ ( $\mathrm{Tr} \times \mathrm{H})$ contributes to adversity adaptation and pathogenicity of Edwardsiella piscicida. Vet Res 50:26

39. Hu YH, Chen L, Sun L (2011) CXCL8 of Scophthalmus maximus: expression, biological activity, and immunoregulatory effect. Dev Comp Immunol 35:1032-1039

40. Wang F, Cheng S, Sun K, Sun L (2008) Molecular analysis of the fur (ferric uptake regulator) gene of a pathogenic Edwardsiella tarda strain. J Microbiol 46:350-355

41. Hu YH, Wang HL, Zhang M, Sun L (2009) Molecular analysis of the copperresponsive CopRSCD of a pathogenic Pseudomonas fluorescens strain. J Microbiol 47:277-286

42. LaMattina JW, Delrossi M, Uy KG, Keul ND, Nix DB, Neelam AR, Lanzilotta WN (2017) Anaerobic heme degradation: ChuY is an anaerobilin reductase that exhibits kinetic cooperativity. Biochemistry 56:845-855

43. Zhou G, Peng H, Wang YS, Huang XM, Xie XB, Shi QS (2017) Complete genome sequence of Citrobacter werkmanii strain BF-6 isolated from industrial putrefaction. BMC Genomics 18:765

44. Wyckoff EE, Duncan D, Torres AG, Mills M, Maase K, Payne SM (1998) Structure of the Shigella dysenteriae haem transport locus and its phylogenetic distribution in enteric bacteria. Mol Microbiol 28:1139-1152

45. Liu X, Gong J, Wei T, Wang Z, Du Q, Zhu D, Huang Y, Xu S, Gu L (2012) Crystal structure of HutZ, a heme storage protein from Vibrio cholerae: a structural mismatch observed in the region of high sequence conservation. BMC Struct Biol 12:23

46. Uchida T, Ota K, Sekine Y, Dojun N, Ishimori K (2019) Subunit-subunit interactions play a key role in the heme-degradation reaction of HutZ from Vibrio cholerae. Dalton Trans 48:3973-3983

47. Foster JW, Hall HK (1992) Effect of Salmonella typhimurium ferric uptake regulator (fur) mutations on iron- and $\mathrm{pH}$-regulated protein synthesis. J Bacteriol 174:4317-4323

48. Ebanks RO, Goguen M, Knickle L, Dacanay A, Leslie A, Ross NW, Pinto DM (2013) Analysis of a ferric uptake regulator (Fur) knockout mutant in Aeromonas salmonicida subsp. salmonicida. Vet Microbiol 162:831-841

49. Zhu C, Ngeleka M, Potter AA, Allan BJ (2002) Effect of fur mutation on acid-tolerance response and in vivo virulence of avian septicemic Escherichia coli. Can J Microbiol 48:458-462

50. Li MF, Sun L, Li J (2015) Edwardsiella tarda evades serum killing by preventing complement activation via the alternative pathway. Fish Shellfish Immunol 43:325-329

51. Zhou ZJ, Sun BG, Sun L (2015) Edwardsiella tarda Sip1: a serum-induced zinc metalloprotease that is essential to serumresistance and host infection. Vet Microbiol 177:332-340

52. Wang C, Hu YH, Sun BG, Li J, Sun L (2013) Edwardsiella tarda Ivy, a lysozyme inhibitor that blocks the lytic effect of lysozyme and facilitates host infection in a manner that is dependent on the conserved cysteine residue. Infect Immun 81:3527-3533

53. Sharma G, Sharma S, Sharma P, Chandola D, Dang S, Gupta S, Gabrani R (2016) Escherichia coli biofilm: development and therapeutic strategies. J Appl Microbiol 121:309-319

54. Liu YL, He TT, Liu LY, Yi J, Nie P, Yu HB, Xie HX (2019) The Edwardsiella piscicida type III translocon protein EseC inhibits biofilm formation by sequestering EseE. Appl Environ Microbiol 85:e02133-18

55. Xiao J, Wang Q, Liu Q, Xu L, Wang X, Wu H, Zhang Y (2009) Characterization of Edwardsiella tarda rpos: effect on serum resistance, chondroitinase activity, biofilm formation, and autoinducer synthetases expression. Appl Microbiol Biotechnol 83:151-160

56. LvY, Zheng J, Yang M, Wang Q, Zhang Y (2012) An Edwardsiella tarda mutant lacking UDP-glucose dehydrogenase shows pleiotropic phenotypes, attenuated virulence, and potential as a vaccine candidate. Vet Microbiol 160:506-512

57. Gao ZP, Nie P, Lu JF, Liu LY, Xiao TY, Liu W, Liu JS, Xie HX (2015) Type III secretion system translocon component EseB forms filaments on and mediates autoaggregation of and biofilm formation by Edwardsiella tarda. Appl Environ Microbiol 81:6078-6087

58. Xu Y, Xu T, Wang B, Dong $X$, Sheng A, Zhang XH (2014) A mutation in $r c s B$, a gene encoding the core component of the Rcs cascade, enhances the virulence of Edwardsiella tarda. Res Microbiol 165:226-232

59. Wang K, Liu E, Song S, Wang X, Zhu Y, Ye J, Zhang H (2012) Characterization of Edwardsiella tarda rpoN: roles in $\sigma(70)$ family regulation, growth, stress adaption and virulence toward fish. Arch Microbiol 194:493-504 
60. He Y, Xu T, Fossheim LE, Zhang XH (2012) FliC, a flagellin protein, is essential for the growth and virulence of fish pathogen Edwardsiella tarda. PLoS One 7:e45070

61. Xu T, Su Y, Xu Y, He Y, Wang B, Dong X, Li Y, Zhang XH (2014) Mutations of flagellar genes fliC12, fliA and flhDC of Edwardsiella tarda attenuated bacterial motility, biofilm formation and virulence to fish. J Appl Microbiol 116:236-244

62. Dong X, Fan X, Wang B, Shi X, Zhang XH (2013) Invasin of Edwardsiella tarda is essential for its haemolytic activity, biofilm formation and virulence towards fish. J Appl Microbiol 115:12-19

63. Gu D, Zhang J, Hao Y, Xu R, Zhang Y, Ma Y, Wang Q (2019) Alternative sigma factor RpoX is a part of RpoE regulon and plays distinct roles in stress response, motility, biofilm formation and hemolytic activities in the marine pathogen Vibrio alginolyticus. Appl Environ Microbiol 85:e00234-19

64. Chen L, Qiu Y, Tang H, Hu LF, Yang WH, Zhu XJ, Huang XX, Wang T, Zhang $Y Q$ (2018) ToxR is required for biofilm formation and motility of Vibrio Parahaemolyticus. Biomed Environ Sci 31:848-850
65. Septer AN, Wang Y, Ruby EG, Stabb EV, Dunn AK (2011) The heme-uptake gene cluster in Vibrio fischeri is regulated by Fur and contributes to symbiotic colonization. Environ Microbiol 13:2855-2864

66. Hu YH, Sun L (2016) The global regulatory effect of Edwardsiella tarda Fur on iron acquisition, stress resistance, and host infection: a proteomicsbased interpretation. J Proteomics 140:100-110

67. Troxell B, Hassan HM (2013) Transcriptional regulation by ferric uptake regulator (Fur) in pathogenic bacteria. Front Cell Infect Microbiol 3:59

\section{Publisher's Note}

Springer Nature remains neutral with regard to jurisdictional claims in published maps and institutional affiliations.
Ready to submit your research? Choose BMC and benefit from:

- fast, convenient online submission

- thorough peer review by experienced researchers in your field

- rapid publication on acceptance

- support for research data, including large and complex data types

- gold Open Access which fosters wider collaboration and increased citations

- maximum visibility for your research: over $100 \mathrm{M}$ website views per year

At BMC, research is always in progress.

Learn more biomedcentral.com/submissions 